\title{
Curcumin: Getting Back to the Roots
}

\author{
SHISHIR SHISHODIA, GAUTAM SETHI, AND BHARAT B. AGGARWAL \\ Cytokine Research Laboratory, Department of Experimental Therapeutics, \\ The University of Texas M. D. Anderson Cancer Center, Houston, Texas 77030, USA
}

\begin{abstract}
The use of turmeric, derived from the root of the plant Curcuma longa, for treatment of different inflammatory diseases has been described in Ayurveda and in traditional Chinese medicine for thousands of years. The active component of turmeric responsible for this activity, curcumin, was identified almost two centuries ago. Modern science has revealed that curcumin mediates its effects by modulation of several important molecular targets, including transcription factors (e.g., NF-кB, AP-1, Egr-1, $\beta$-catenin, and PPAR- $\gamma$ ), enzymes (e.g., COX2, 5-LOX, iNOS, and hemeoxygenase-1), cell cycle proteins (e.g., cyclin D1 and p21), cytokines (e.g., TNF, IL-1, IL-6, and chemokines), receptors (e.g., EGFR and HER2), and cell surface adhesion molecules. Because it can modulate the expression of these targets, curcumin is now being used to treat cancer, arthritis, diabetes, Crohn's disease, cardiovascular diseases, osteoporosis, Alzheimer's disease, psoriasis, and other pathologies. Interestingly, 6-gingerol, a natural analog of curcumin derived from the root of ginger (Zingiber officinalis), exhibits a biologic activity profile similar to that of curcumin. The efficacy, pharmacologic safety, and cost effectiveness of curcuminoids prompt us to "get back to our roots."
\end{abstract}

KEYWORDS: curcumin; antioxidant; anti-tumor; curcumin analogs

\section{INTRODUCTION}

The turmeric (Curcuma longa) plant, a perennial herb belonging to the ginger family, is cultivated extensively in south and southeast tropical Asia. The rhizome of this plant is also referred to as the "root" and is the most useful part of the plant for culinary and medicinal purposes. The most active component of turmeric is curcumin, which makes up $2-5 \%$ of the spice. The characteristic yellow color of turmeric is due to the curcuminoids, first isolated by Vogel in 1842. Curcumin is an orange-yellow crystalline powder practically insoluble in water. The structure of curcumin $\left(\mathrm{C}_{21} \mathrm{H}_{20} \mathrm{O}_{6}\right)$ was first described in 1910 by Lampe and Milobedeska and shown to be diferuloylmethane. ${ }^{1}$

Turmeric is used as a dietary spice, coloring agent in foods and textiles, and a treatment for a wide variety of ailments. It is widely used in traditional Indian medicine to cure biliary disorders, anorexia, cough, diabetic wounds, hepatic disorders, rheumatism, and sinusitis. Turmeric paste in slaked lime is a popular home remedy

Address for correspondence: Bharat B. Aggarwal, Cytokine Research Laboratory, Department of Experimental Therapeutics, The University of Texas M. D. Anderson Cancer Center, Box 143, 1515 Holcombe Boulevard, Houston, TX 77030. Voice: 713-792-3503/6459; fax: 713-794-1613. aggarwal@mdanderson.org

Ann. N.Y. Acad. Sci. 1056: 206-217 (2005). @ 2005 New York Academy of Sciences. doi: 10.1196/annals.1352.010 
for the treatment of inflammation and wounds. For centuries, curcumin has been consumed as a dietary spice at doses up to $100 \mathrm{mg} /$ day. Recent phase I clinical trials indicate that human beings can tolerate a dose as high as $8 \mathrm{~g} /$ day with no side effects. $^{2}$ The focus of this review is to describe the effect of curcumin in various diseases.

\section{DISEASE TARGETS OF CURCUMIN}

Ancient texts of Indian medicine describe the use of curcumin for a wide variety of inflammatory diseases including sprains and swellings caused by injury, wound healing, and abdominal problems. ${ }^{3}$ Texts on traditional medicine in China describe the uses of curcumin for the treatment of diseases that are associated with abdominal pain. There are over 1,500 citations in Medline relating to the biologic effect of curcumin. Perhaps most of the activities associated with curcumin are based on its ability to suppress inflammation. Curcumin has been shown to be effective in acute as well as chronic models of inflammation.

Antiinflammatory and Antioxidant Properties. Several studies have shown that curcumin is a potent antioxidant (FIG. 1). In fact, curcumin has been found to be at least 10 times more active as an antioxidant than even vitamin E. ${ }^{4}$ Curcumin prevents the oxidation of hemoglobin and inhibits lipid peroxidation (for references see Ref. 1). The antioxidant activity of curcumin could be mediated through antioxidant enzymes such as superoxide dismutase, catalase, and glutathione peroxidase. Curcumin has been shown to serve as a Michael acceptor reacting with glutathione and thioredoxin $1 .^{5}$ Reaction of curcumin with these agents reduces intracellular GSH in

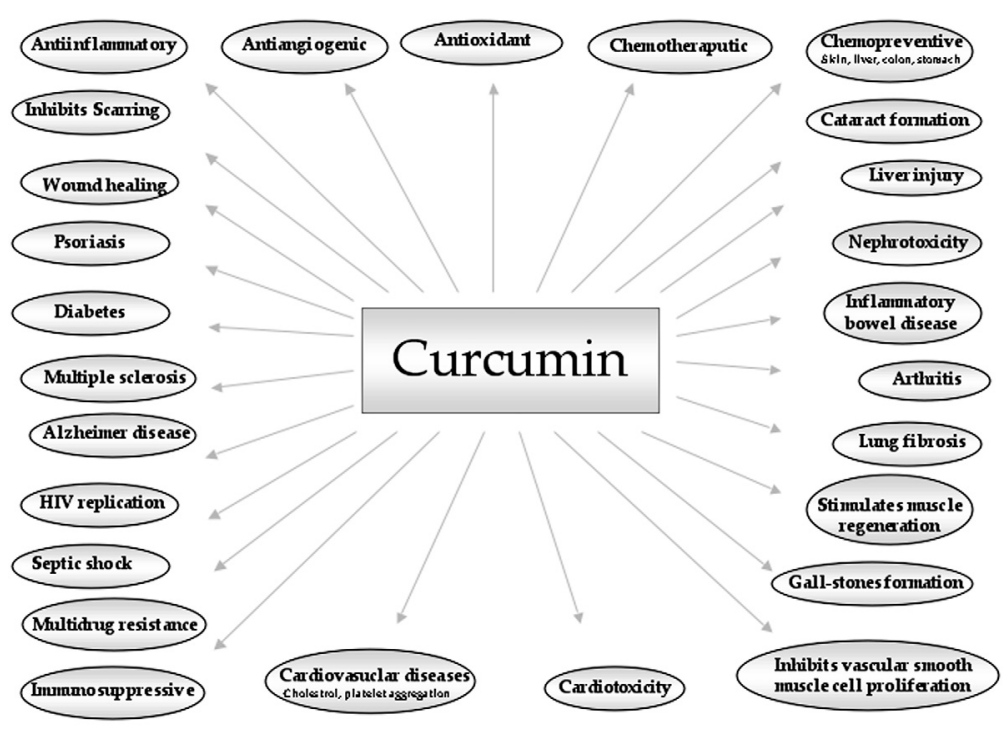

FIGURE 1. Disease targets of curcumin. 
the cells. The suppression of lipid peroxidation by curcumin could lead to suppression of inflammation.

Anticancer Properties. The anticancer potential of curcumin in various systems was recently reviewed. ${ }^{1}$ Curcumin has been shown to block transformation, tumor initiation, tumor promotion, invasion, angiogenesis, and metastasis. In vivo, curcumin suppresses carcinogenesis of the skin, forestomach, colon, and liver in mice. Curcumin also suppresses mammary carcinogenesis. Curcumin has been shown to inhibit the proliferation of a wide variety of tumor cells, including B-cell and T-cell leukemia, colon carcinoma, epidermoid carcinoma, and various breast carcinoma cells.

Cardioprotective Effects. Curcumin has been effective against atherosclerosis and myocardial infarction. ${ }^{6}$ The proliferation of peripheral blood mononuclear cells (PBMCs) and vascular smooth muscle cells (VSMCs), which are hallmarks of atherosclerosis, is inhibited by curcumin. Curcumin prevents the oxidation of lowdensity lipoproteins (LDLs), inhibits platelet aggregation, and reduces the incidence of myocardial infarction.

Skin Diseases. Curcumin has been shown to be effective against different skin diseases including skin carcinogenesis, psoriasis, ${ }^{7}$ scleroderma, ${ }^{8}$ and dermatitis. Numerous reports suggest that curcumin accelerates wound healing. In addition, curcumin also prevents the formation of scars and plays a role in muscle regeneration following trauma. ${ }^{6}$

Diabetes. In type II diabetes, administration of curcumin reduced the blood sugar, hemoglobin, and glycosylated hemoglobin levels significantly in an alloxan-induced diabetic rat model. Diabetic rats maintained on a curcumin diet for 8 weeks excreted less albumin, urea, creatinine, and inorganic phosphorus. Dietary curcumin also partially reversed the abnormalities in plasma albumin, urea, creatine, and inorganic phosphorus in diabetic animals. ${ }^{6}$

Rheumatoid Arthritis. Curcumin has also been shown to possess antirheumatic and antiarthritic effects, most likely through the downregulation of COX2, tumor necrosis factor (TNF), and other inflammatory cytokines. ${ }^{6}$

Multiple Sclerosis. Multiple sclerosis is characterized by the destruction of oligodendrocytes and myelin sheath in the CNS. Curcumin inhibits experimental allergic encephalomyelitis by blocking interleukin (IL)-12 signaling in T cells, suggesting it would be effective in the treatment of multiple sclerosis. ${ }^{6}$

Alzheimer's Disease. Curcumin can suppress oxidative damage, inflammation, cognitive deficits, and amyloid accumulation in Alzheimer's disease. ${ }^{9}$

Inflammatory Bowel Disease. Ukil et al. ${ }^{10}$ recently investigated the protective effects of curcumin on inflammatory bowel disease induced in a mouse model. Pretreatment of mice with curcumin for 10 days significantly ameliorated the appearance of diarrhea and the disruption of the colonic architecture.

Cystic Fibrosis. Cystic fibrosis, the most common lethal hereditary disease in the white population, is caused by mutations in the cystic fibrosis transmembrane conductance regulator gene. In a recent report, Egan et al. ${ }^{11}$ demonstrated that curcumin corrected the cystic fibrosis defects in DeltaF508 CF mice.

Others. Curcumin was found to be a potent and selective inhibitor of human immunodeficiency virus (HIV-1) long-terminal repeat-directed gene expression, which governs the transcription of type $1 \mathrm{HIV}-1$ provirus. It has also been shown to prevent cataractogenesis in an in vitro rat model. Treatment with curcumin also pre- 
vented experimental alcoholic liver disease. Curcumin has a protective effect on cyclophosphamide-induced early lung injury. Nephrotoxicity, a problem observed in patients who are administered chemotherapeutic agents, can be prevented with curcumin. $^{6}$

\section{MOLECULAR TARGETS OF CURCUMIN}

Various studies have shown that curcumin modulates numerous targets (FIG. 2). These include the growth factors, growth factor receptors, transcription factors, cytokines, enzymes, and genes regulating apoptosis.

Cytokines and Growth Factors. Numerous growth factors have been implicated in the growth and promotion of tumors. Curcumin has been shown to downregulate the expression of several cytokines including TNF, IL-6, IL-8, IL-12, and fibroblast growth factor- $2 .^{6}$

Receptors. Curcumin has been shown to downregulate both epithelial growth factor receptor (EGFR) and HER2/neu receptors. It also modulates androgen receptors. 6

Transcription Factors. Curcumin may also operate through suppression of various transcription factors including NF- $\mathrm{BB}$, STAT3, Egr-1, AP-1, PPAR- $\gamma$, and beta catenin activation. ${ }^{6}$ These transcription factors play an essential role in various diseases. The constitutively active form of $\mathrm{NF}-\kappa \mathrm{B}$ has been reported in a wide variety of cancers. NF- $\mathrm{KB}$ is required for the expression of genes involved in cell proliferation, cell invasion, metastasis, angiogenesis, and resistance to chemotherapy. Bharti et al. ${ }^{12}$ demonstrated that curcumin inhibited IL-6-induced STAT3 phosphorylation

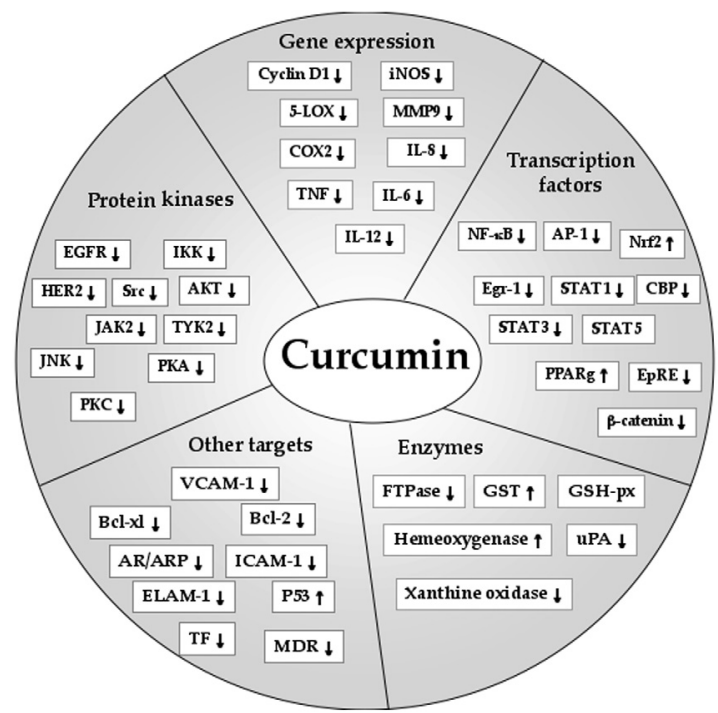

FIGURE 2. Molecular targets of curcumin. 
and consequent STAT3 nuclear translocation. Activation of PPAR- $\gamma$ inhibits the proliferation of nonadipocytes. Xu et al. ${ }^{13}$ demonstrated that curcumin dramatically induced the gene expression of PPAR- $\gamma$ and activated PPAR- $\gamma$. AP- 1 , another transcription factor that has been closely linked with proliferation and transformation of tumor cells, has been shown to be suppressed by curcumin. Studies also suggest that curcumin has a potential therapeutic effect on prostate cancer cells through downregulation of AR and AR-related cofactors. ${ }^{6}$

Proinflammatory Enzymes. Curcumin has been shown to suppress the expression of COX2, 5-LOX, and iNOS, most likely through the downregulation of NF- $\mathrm{KB}$ activation. ${ }^{6}$

Protein Kinases. Curcumin suppresses a number of protein kinases including mitogen-activated protein kinases, JNK, PKA, PKC, src tyrosine kinase, phosphorylase kinase, I $\mathrm{KB} \alpha$ kinase, JAK kinase, and the growth factor receptor protein tyrosine kinases. ${ }^{6}$

Cell Cycle. Curcumin modulates cell-cycle-related gene expression. Specifically, curcumin induced G0/G1 and/or G2/M phase cell cycle arrest, upregulated CDKIs, p21WAF1/CIP1, p27KIP1, and p53, and slightly downregulated cyclin B1 and cdc2. We found that curcumin can indeed downregulate cyclin D1 expression ${ }^{14-16}$ at the transcriptional and posttranscriptional levels.

Adhesion Molecules. Curcumin inhibits inflammation by blocking the adhesion of monocytes to endothelial cells by inhibiting the activation of the cell adhesion molecules ICAM-1, VCAM-1, and ELAM- $1{ }^{6}$

Antiapoptotic Proteins. Curcumin induces apoptosis by inducing cytochrome $c$ release, Bid cleavage, and caspase 9 and 3 activation and by downregulating the antiapoptotic proteins $\mathrm{Bcl}-2$ and $\mathrm{BclX}_{\mathrm{L} .}{ }^{1}$

Multidrug Resistance. Multidrug resistance is associated with decreased drug accumulation in tumor cells due to increased drug efflux. Curcumin downregulates drug resistance by inhibiting the expression of the mdr gene, which is responsible for this phenomenon. ${ }^{6}$

\section{LESSONS LEARNED FROM SYNTHETIC ANALOGS OF CURCUMIN}

To elucidate which portion of the molecule is critical for the activity, a large number of structural analogs of curcumin have been synthesized (FIG. 3A). Some analogs are more active than native curcumin, whereas others are less active ${ }^{17-32}$ (TABLE 1). It was found that the phenolic analogs were more active than the nonphenolic ana$\operatorname{logs} .{ }^{33}$ The highest antioxidant activity was obtained when the phenolic group was sterically hindered by the introduction of two methyl groups at the ortho position. The phenolic group is essential for free radical scavenging activity, and the presence of the methoxy group further increases the activity. ${ }^{34}$ Curcumin shows both antioxidant and pro-oxidant effects. Ahsan et al. ${ }^{35}$ have shown that both of these effects are determined by the same structural moieties of the curcuminoids.

Dinkova-Kostova and Talalay ${ }^{30}$ showed that the presence of hydroxyl groups at the ortho-position on the aromatic rings and the beta-diketone functionality were required for high potency in inducing Phase 2 detoxification enzymes. Curcumin is a noncompetitive inhibitor of rat liver microsomal delta 5 desaturase and delta 6 desaturase. Kawashima et al. ${ }^{36}$ have shown that only half the structure is essential 
TABLE 1. Relative potency of curcumin and its synthetic analogs

\begin{tabular}{|c|c|}
\hline Effects & References \\
\hline \multicolumn{2}{|l|}{ Analogs more potent than curcumin } \\
\hline $\begin{array}{l}\text { THC: lipid peroxidation under aqueous condition by pulse radiolysis } \\
\text { technique }\end{array}$ & 17 \\
\hline HC: preventing nitrite-induced oxidation of haemoglobin & 18 \\
\hline NaC: carrageenin-induced rat hind paw edema & 19 \\
\hline HMBME: inhibition of prostate cancer & 20 \\
\hline $\begin{array}{l}\text { BJCO05, CHC011, and CHC007: formation of Fos-/Jun- DNA } \\
\text { complex }\end{array}$ & 21 \\
\hline Tocopheryl curcumin: inhibiting Tat transactivation of HIV-LTR & 22 \\
\hline 4,4'-DAC : histamine blocking activity & 23 \\
\hline Copper chelates of 2-hydroxynapthyl curcumin: antitumor activity & 24 \\
\hline Hydrazinocurcumin: BAECs proliferation & 25 \\
\hline $\begin{array}{l}\text { o-hydroxy substituted analog: inhibiting alcohol and PUFA induced } \\
\text { oxidative stress }\end{array}$ & 26 \\
\hline $\begin{array}{l}\text { Di-O-glycinoyl curcumin and } 2^{\prime} \text {-deoxy-2'-curcuminyl uridine: } \\
\text { antiviral activity }\end{array}$ & 27 \\
\hline Pyrazole and isoxazole analogs: Cox-2 inhibitory activity & 28 \\
\hline $\begin{array}{l}\text { 1,7-bis-(2-hydroxy-4-methoxyphenyl)-1,6-heptadiene-3,5-dione): } \\
\text { AL activity }\end{array}$ & 29 \\
\hline \multicolumn{2}{|l|}{ Salicylcurcuminoid: antioxidant } \\
\hline \multicolumn{2}{|l|}{ Analogs less potent than curcumin } \\
\hline $\begin{array}{l}\text { THC: lipid peroxidation under aerated condition by pulse radiolysis } \\
\text { technique }\end{array}$ & 17 \\
\hline THC: TPA-induced mouse ear edema and skin carcinogenesis & 30 \\
\hline \multicolumn{2}{|l|}{ Analogs as potent as curcumin } \\
\hline $\begin{array}{l}\text { 5-hydroxy-1,7-diphenyl-1,4,6-heptatriene-3-one: Scavenge hydroxyl } \\
\text { radicals }\end{array}$ & 31 \\
\hline $\begin{array}{l}\text { Manganese complexes of curcumin and diacetylcurcumin: } \\
\text { Scavenge hydroxyl radicals }\end{array}$ & 32 \\
\hline
\end{tabular}

ABBREVIATIONS: THC, tetrahydrocurcumin; NaC, sodium curcuminate; HMBME, 4-hydroxy3-methoxybenzoic acid methyl ester; DAC, diacetylcurcumin; BAEC, bovine aortic endothelial cells; PUFA, thermally oxidized sunflower oil; Cox-2, cyclooxygenase-2; AL, anti-leishmanial.

for desaturase inhibition. A 3-hydroxy group of the aromatic ring is essential for the inhibition, and a free carboxyl group at the end opposite the aromatic ring interferes with the inhibitory effect.

Simon et al. ${ }^{37}$ found that the presence of the diketone moiety in the curcumin molecule seems to be essential for its ability to inhibit the proliferation of MCF-7 human breast tumor cells. The aromatic enone and dienone analogs of curcumin were demonstrated to have potent antiangiogenic properties in an in vitro SVR assay. $^{38}$ 


\section{A}

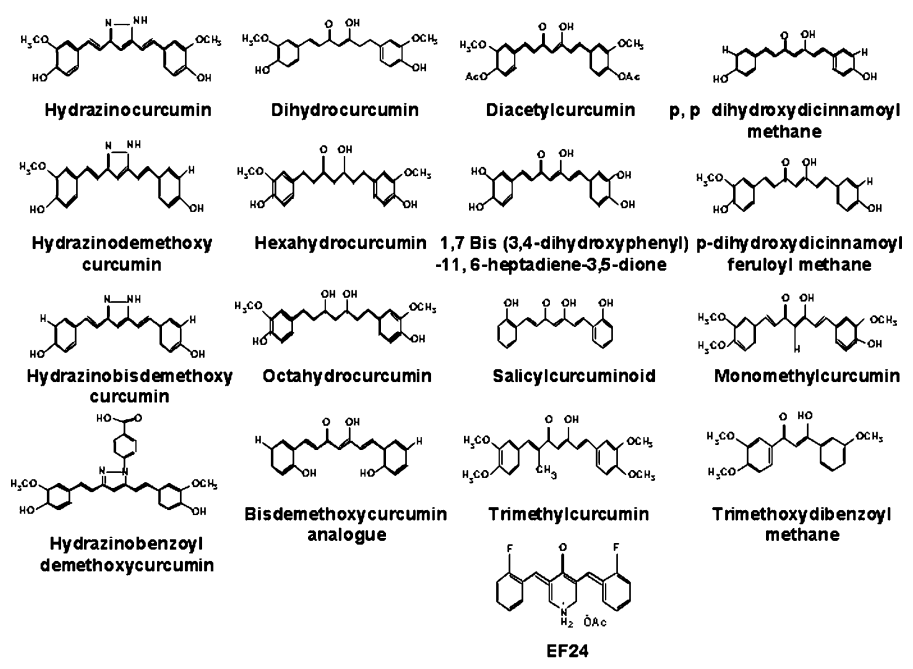

B

$$
\text { (1)-Paradol }
$$

FIGURE 3. Structure of various analogs of curcumin. Hydrazinocurcumin,${ }^{25}$ hydrazinodemethoxycurcumin, ${ }^{25}$ hydrazinobisdemethoxycurcumin, ${ }^{25}$ hydrazinobenzoyldemethoxycurcumin, ${ }^{25}$ dihydrocurcumin, ${ }^{50}$ hexahydrocurcumin, ${ }^{51}$ octahydrocurcumin,${ }^{51}$ bisdemethoxycurcumin, ${ }^{52}$ diacetylcurcumin, ${ }^{51}$ salicylcurcuminoid, ${ }^{30}$ monomethylcurcumin,${ }_{53}$ trimethylcurcumin, ${ }^{53}$ and 7-bis(3,-4-dihydroxyphenyl) 11,6-heptadiene-3,5dione. 53 
TABLE 2. Sources and site of action of natural analogs of curcumin ${ }^{a}$

\begin{tabular}{|c|c|c|c|}
\hline Analogs & Source & Target & Ref \\
\hline 6-Gingerol & Ginger (Zingiber officinale Roscoe) & $\begin{array}{l}\text { TNF, NF- } \mathrm{\kappa B}, \text { AP-1, } \\
\text { COX2, ODC, iNOS, } \\
\text { p38MAPK, antifungal }\end{array}$ & 39 \\
\hline 8-Gingerol & Ginger (Zingiber officinale Roscoe) & & 39 \\
\hline 6-Paradol & Ginger (Zingiber officinale Roscoe) & Caspase activation & 40 \\
\hline Shogoal & Ginger (Zingiber officinale Roscoe) & Helicobacter pylori & 41 \\
\hline Cassumunin A\&B & Ginger (Zingiber cassumunar) & Antioxidant & 42 \\
\hline Diarylheptanoids & Ginger (Zingiber spp.) & PGE2 and LT & 43 \\
\hline Dibenzoylmethane & Licorice (Glycyrrhiza echinata) & $\begin{array}{l}\text { COX2, LOX, HIF, } \\
\text { VEGF }\end{array}$ & 43 \\
\hline Galanals A\&B & Zingiber (Zingiber mioga Roscoe) & Caspase 3, bcl 2 & 44 \\
\hline Garcinol & Kokum (Garcinia indica) & $\begin{array}{l}\text { NF- } \mathrm{kB}, \mathrm{COX}-2 \text {, iNOS, } \\
\text { HAT }\end{array}$ & 45 \\
\hline Isoeugenol & Cloves (Eugenia caryophyllus) & $\begin{array}{l}\text { NF- } \kappa \mathrm{B} \text {, antioxidant } \\
\beta \text {-amyloid }\end{array}$ & 46 \\
\hline Yakuchinone A\&B & Galanga (Alpinia officinarum) & $\begin{array}{l}\text { PG synthetase, COX2, } \\
\text { iNOS, NF-kB, } \\
\text { insecticidal, adhesion } \\
\text { molecules, TNF, } \\
\text { AP-1, 5-HETE }\end{array}$ & 47 \\
\hline
\end{tabular}

${ }^{a}$ For structure of these analogs, see FigURE 3.

\section{NATURAL ANALOGS OF CURCUMIN}

Natural curcumin contains three major curcuminoids, namely, curcumin, demethoxycurcumin, and bisdemethoxycurcumin (FIG. 3B). Several analogs of curcumin have been identified from other plant sources. These include 6- and 8gingerol, 6-paradol, cassumunin, galanals, diarylheptanoids, yakuchinones, isoeugenol, and dibenzoylmethane. Like curcumin, gingerol, paradol, cassumunin, shogaol, and diarylheptanoids are also derived from the roots of the plant (TABLE 2). ${ }^{39-47}$ Although most of these analogs exhibit activities very similar to those of curcumin, whether they are more potent or less potent than curcumin has not been established. Yakuchinones ${ }^{48}$ have been shown to be more potent inhibitors of 5HETE production than curcumin. Synthetic cassumunins also show stronger protective activity than curcumin against oxidative cell death induced by hydrogen peroxide. $^{42}$ Garcinol is more potent than curcumin in inhibiting tumor cells. ${ }^{45}$ The anticancer potential of galanals, however, is comparable to that of curcumin. ${ }^{44} \mathrm{Cur}$ cumin has been shown to be more cytotoxic than isoeugenol, bis-eugenol, and eugenol. 49 


\section{CONCLUSION}

The medicinal properties of curcumin and its analogs have been known to mankind for ages. Modern science has now provided a scientific basis to the numerous reports of the medicinal effects of these most inexpensive, yet pharmacologically safe, polyphenols. Extensive research in the last few years has indicated that most diseases are caused by the dysregulation of multiple signaling pathways, thus casting doubt on how effective monotherapy against single targets will prove to be. Curcumin and its analogs have been found to attack multiple targets, which provides the basis for their effectiveness in so many different diseases. Although most of the NSAIDS are now either withdrawn or survive with black box warnings, curcumin is one that is not known to show any adverse effects, even at doses as high as $8 \mathrm{~g}$ a day. Thus, a trip back to our "roots" to explore the "roots" of Curcuma longa as a source for better treatments will certainly prove productive. As Hippocrates said almost 25 centuries ago, "let food be thy medicine and medicine be thy food."

\section{ACKNOWLEDGMENTS}

We would like to thank Walter Pagel for a careful review of the manuscript. Dr. Aggarwal is a Ransom Horne Jr. Distinguished Professor of Cancer Research. This work was supported in part by the Odyssey Program and the Theodore N. Law Award for Scientific Achievement at The University of Texas M. D. Anderson Cancer Center (to S.S.).

\section{REFERENCES}

1. Aggarwal, B.B., A. Kumar \& A.C. Bharti. 2003. Anticancer potential of curcumin: preclinical and clinical studies. Anticancer Res. 23: 363-398.

2. Cheng, A.L., C.H. Hsu, J.K. Lin, et al. 2001. Phase I clinical trial of curcumin, a chemopreventive agent, in patients with high-risk or pre-malignant lesions. Anticancer Res. 21: 2895-2900.

3. Ammon, H.P. \& M.A. WAHL. 1991. Pharmacology of Curcuma longa. Planta Med. 57: $1-7$.

4. Khopde, S.M., K.I. Priyadarsini, P. Venkatesan, et al. 1999. Free radical scavenging ability and antioxidant efficiency of curcumin and its substituted analogue. Biophys. Chem. 80: 85-91.

5. Adams, B.K., J. CAI, J. Armstrong, et al. 2005. EF24, a novel synthetic curcumin analog, induces apoptosis in cancer cells via a redox-dependent mechanism. Anticancer Drugs 16: 263-275.

6. Aggarwal, B.B., A. Kumar, M.S. Aggarwal, et al. 2005. Curcumin derived from turmeric (Curcuma longa): a spice for all seasons. In Phytochemicals in Cancer Chemoprevention. P.D. Debasis Bagchi \& H.G. Preuss, Eds. :349-387. CRC Press. New York.

7. Heng, M.C., M.K. Song, J. Harker, et al. 2000. Drug-induced suppression of phosphorylase kinase activity correlates with resolution of psoriasis as assessed by clinical, histological and immunohistochemical parameters. Br. J. Dermatol. 143: 937949.

8. Tourkina, E., P. Gooz, J.C. OAtes, et al. 2004. Curcumin-induced apoptosis in scleroderma lung fibroblasts: role of protein kinase cepsilon. Am. J. Respir. Cell Mol. Biol. 31: $28-35$. 
9. Yang, F., G.P. Lim, A.N. Begum, et al. 2005. Curcumin inhibits formation of amyloid beta oligomers and fibrils, binds plaques, and reduces amyloid in vivo. J. Biol. Chem. 280: 5892-5901.

10. Ukil, A., S. Maity, S. Karmakar, et al. 2003. Curcumin, the major component of food flavour turmeric, reduces mucosal injury in trinitrobenzene sulphonic acidinduced colitis. Br. J. Pharmacol. 139: 209-218.

11. Egan, M.E., M. Pearson, S.A. Weiner, et al. 2004. Curcumin, a major constituent of turmeric, corrects cystic fibrosis defects. Science 304: 600-602.

12. Bharti, A.C., N. Donato \& B.B. Aggarwal. 2003. Curcumin (diferuloylmethane) inhibits constitutive and IL-6-inducible STAT3 phosphorylation in human multiple myeloma cells. J. Immunol. 171: 3863-3871.

13. XU, J., Y. Fu \& A. CHEN. 2003. Activation of peroxisome proliferator-activated receptor-gamma contributes to the inhibitory effects of curcumin on rat hepatic stellate cell growth. Am. J. Physiol. Gastrointest. Liver Physiol. 285: G20-30.

14. Bharti, A.C., N. Donato, S. Singh, et al. 2003. Curcumin (diferuloylmethane) downregulates the constitutive activation of nuclear factor-kappa B and IkappaBalpha kinase in human multiple myeloma cells, leading to suppression of proliferation and induction of apoptosis. Blood 101: 1053-1062.

15. Mukhopadhyay, A., C. Bueso-Ramos, D. Chatterjee, et al. 2001. Curcumin downregulates cell survival mechanisms in human prostate cancer cell lines. Oncogene 20: 7597-7609.

16. Mukhopadhyay, A., S. BanerJee, L.J. Stafford, et al. 2002. Curcumin-induced suppression of cell proliferation correlates with donregulation of cyclin D1 expression and CDK4-mediated retinoblastoma protein phosphorylation. Oncogene 21: 88528862.

17. Khopde, S.M., K.I. Priyadarsini, S.N. Guha, et al. 2000. Inhibition of radiationinduced lipid peroxidation by tetrahydrocurcumin: possible mechanisms by pulse radiolysis. Biosci. Biotechnol. Biochem. 64: 503-509.

18. Venkatesan, P., M.K. UnNikrishnan, S.M. Kumar, et al. 2003. Effect of curcumin analogues on oxidation of haemoglobin and lysis of erythrocytes. Curr. Sci. 84: 74-78.

19. RaO, T.S., N. Basu \& H.H. SiddiQui. 1982. Anti-inflammatory activity of curcumin analogues. Indian J. Med. Res. 77: 574-578.

20. Kumar, A.P., G.E. Garcia, R. Ghosh, et al. 2003. 4-Hydroxy-3-methoxybenzoic acid methyl ester: a curcumin derivative targets Akt/NF kappa B cell survival signaling pathway: potential for prostate cancer management. Neoplasia 5: 255-266.

21. HAhm, E.R., G. CheOn, J. LeE, et al. 2002. New and known symmetrical curcumin derivatives inhibit the formation of Fos-Jun-DNA complex. Cancer Lett. 184: 89-96.

22. Barthelemy, S., L. Vergnes, M. Moynier, et al. 1998. Curcumin and curcumin derivatives inhibit Tat-mediated transactivation of type 1 human immunodeficiency virus long terminal repeat. Res. Virol. 149: 43-52.

23. Douglas, D.E. 1993. 4,4'-Diacetyl curcumin: in-vitro histamine-blocking activity. J. Pharm. Pharmacol. 45: 766.

24. John, V.D., G. KutTan \& K. Krishnankutty. 2002. Anti-tumour studies of metal chelates of synthetic curcuminoids. J. Exp. Clin. Cancer Res. 21: 219-224.

25. Shim, J.S., D.H. KIM, H.J. Jung, et al. 2002. Hydrazinocurcumin, a novel synthetic curcumin derivative, is a potent inhibitor of endothelial cell proliferation. Bioorg. Med. Chem. 10: 2439-2444.

26. Rukkumani, R., K. Aruna, P.S. Varma, et al. 2004. Comparative effects of curcumin and an analog of curcumin on alcohol and PUFA induced oxidative stress. J. Pharm. Pharm. Sci. 7: 274-283.

27. Mishra, S., S. Tripathi \& K. Misra. 2002. Synthesis of a novel anticancer prodrug designed to target telomerase sequence. Nucleic Acids Res. (Suppl.) 2: 277-278.

28. Selvam, C., S.M. JachaK, R. Thilagavathi, et al. 2005. Design, synthesis, biological evaluation and molecular docking of curcumin analogues as antioxidant, cyclooxygenase inhibitory and anti-inflammatory agents. Bioorg. Med. Chem. Lett. 15: 1793-1797.

29. Gomes Dde, C., L.V. Alegrio, M.E. De Lima, et al. 2002. Synthetic derivatives of curcumin and their activity against Leishmania amazonensis. Arzneimittelforschung 52: $120-124$. 
30. Dinkova-Kostova, A.T. \& P. Talalay. 1999. Relation of structure of curcumin ana$\log$ to their potencies as inducers of Phase 2 detoxification enzymes. Carcinogenesis 20: $911-914$

31. Tonnesen, H.H. \& J.V. Greenhill. 1992. Studies on curcumin and curcuminoids XXII: curcumin as a reducing agent and as a radical scavenger. Int. J. Pharm. 87: 7987.

32. Vajragupta, O., P. Boonchoong \& L.J. Berliner. 2004. Manganese complexes of curcumin analogues: evaluation of hydroxyl radical scavenging ability, superoxide dismutase activity and stability towards hydrolysis. Free Radic. Res. 38: 303-314.

33. Venkatesan, P. \& M.N. RaO. 2000. Structure-activity relationships for the inhibition of lipid peroxidation and the scavenging of free radicals by synthetic symmetrical curcumin analogues. J. Pharm. Pharmacol. 52: 1123-1128.

34. Sreejayan, N. \& M.N. RaO. 1996. Free radical scavenging activity of curcuminoids. Arzneimittelforschung 46: 169-171.

35. Ahsan, H., N. Parveen, N.U. Khan, et al. 1999. Pro-oxidant, anti-oxidant and cleavage activities on DNA of curcumin and its derivatives demethoxycurcumin and bisdemethoxycurcumin. Chem. Biol. Interact. 121: 161-175.

36. Kawashima, H., K. Акimoto, S. JareonkitmongKol, et al. 1996. Inhibition of rat liver microsomal desaturases by curcumin and related compounds. Biosci. Biotechnol. Biochem. 60: 108-110.

37. Simon, A., D.P. Allais, J.L. Duroux, et al. 1998. Inhibitory effect of curcuminoids on MCF-7 cell proliferation and structure-activity relationships. Cancer Lett. 129: 111116.

38. Robinson, T.P., T. Ehlers, I.R. Hubbard, et al. 2003. Design, synthesis, and biological evaluation of angiogenesis inhibitors: aromatic enone and dienone analogues of curcumin. Bioorg. Med. Chem. Lett. 13: 115-117.

39. KIM, S.O., J.K. KUNDU, Y.K. SHIN, et al. 2005. [6]-Gingerol inhibits COX-2 expression by blocking the activation of p38 MAP kinase and NF-kappaB in phorbol esterstimulated mouse skin. Oncogene 24: 2558-2567.

40. KeUm, Y.S., J. KIM, K.H. LEE, et al. 2002. Induction of apoptosis and caspase-3 activation by chemopreventive [6]-paradol and structurally related compounds in KB cells. Cancer Lett. 177: 41-47.

41. Mahady, G.B., S.L. Pendland, G.S. Yun, et al. 2003. Ginger (Zingiber officinale Roscoe) and the gingerols inhibit the growth of Cag A+ strains of Helicobacter pylori. Anticancer Res. 23: 3699-3702.

42. Masuda, T., H. Matsumura, Y. Oyama, et al. 1998. Synthesis of (+/-)-cassumunins $\mathrm{A}$ and $\mathrm{B}$, new curcuminoid antioxidants having protective activity of the living cell against oxidative damage. J. Nat. Prod. 61: 609-613.

43. Hong, J., M. Bose, J. Ju, et al. 2004. Modulation of arachidonic acid metabolism by curcumin and related beta-diketone derivatives: effects on cytosolic phospholipase $\mathrm{A}(2)$, cyclooxygenases and 5-lipoxygenase. Carcinogenesis 25: 1671-1679.

44. Miyoshi, N., Y. NAKamura, Y. Ueda, et al. 2003. Dietary ginger constituents, galanals $\mathrm{A}$ and $\mathrm{B}$, are potent apoptosis inducers in human $\mathrm{T}$ lymphoma Jurkat cells. Cancer Lett. 199: 113-119.

45. Pan, M.H., W.L. Chang, S.Y. Lin-ShiaU, et al. 2001. Induction of apoptosis by garcinol and curcumin through cytochrome $\mathrm{c}$ release and activation of caspases in human leukemia HL-60 cells. J. Agric. Food Chem. 49: 1464-1474.

46. Chainy, G.B., S.K. Manna, M.M. Chaturvedi, et al. 2000. Anethole blocks both early and late cellular responses transduced by tumor necrosis factor: effect on NFkappaB, AP-1, JNK, MAPKK and apoptosis. Oncogene 19: 2943-2950.

47. Chun, K.S., J.Y. KANG, O.H. KIM, et al. 2002. Effects of yakuchinone A and yakuchinone B on the phorbol ester-induced expression of COX-2 and iNOS and activation of NF-kappaB in mouse skin. J. Environ. Pathol. Toxicol. Oncol. 21: 131-139.

48. Flynn, D.L., M.F. RafFerty \& A.M. Boctor. 1986. Inhibition of 5-hydroxy-eicosatetraenoic acid (5-HETE) formation in intact human neutrophils by naturallyoccurring diarylheptanoids: inhibitory activities of curcuminoids and yakuchinones. Prostaglandins Leukot. Med. 22: 357-360. 
49. Fujisawa, S., T. Atsumi, M. Ishihara, et al. 2004. Cytotoxicity, ROS-generation activity and radical-scavenging activity of curcumin and related compounds. Anticancer Res. 24: 563-569.

50. PAN, M.H., T.M. HuANG \& J.K. Lin. 1999. Biotransformation of curcumin through reduction and glucuronidation in mice. Drug Metab. Dispos. 27: 486-494.

51. Ishida, J., H. OHTsu, Y. TAChibana, et al. 2002. Antitumor agents. Part 214: synthesis and evaluation of curcumin analogues as cytotoxic agents. Bioorg. Med. Chem. 10: 3481-3487.

52. Srivivasan, A., V.P. Menon, V. Periaswamy, et al. 2003. Protection of pancreatic beta-cell by the potential antioxidant bis-o-hydroxycinnamoyl methane, analogue of natural curcuminoid in experimental diabetes. J. Pharm. Pharm. Sci. 6: 327-333.

53. Ohtsu, H., Z. XiaO, J. IshidA, et al. 2002. Antitumor agents. 217. Curcumin analogues as novel androgen receptor antagonists with potential as anti-prostate cancer agents. J. Med. Chem. 45: 5037-5042. 